\title{
Design and Implementation of a Tertiary Institution Web-Based Student Complaint Management System
}

\author{
${ }^{1 .}$ Dr. ANUSIUBA Overcomer Ifeanyi Alex ${ }^{2}$ Dr KARIM Usman \\ ${ }^{3}$.EKWEALOR Oluchukwu Uzoamaka, ${ }^{4 .}$ IGBONEKWU Joy Obianuju \\ ${ }^{1,3,4}$ Department of Computer Science, Faculty of Physical Sciences, Nnamdi Azikiwe University \\ Awka \\ 2. Department of Computer Science, Benue State University, Makurdi Nigeria \\ ${ }^{1}$ oi.anusiuba@unizik.edu.ng ${ }^{2}$ zithosting@gmail.com \\ ${ }^{3}$ uzoamakaekwee@gmail.com ${ }^{4}$ joykenneth605@gmail.com
}

DOI: 10.26821/IJSHRE.9.8.2021.9802

\begin{abstract}
The objective of this work is to design and implementation a tertiary institution Web-based Student Complaint Management System. It is no gainsaying that many students face a lot of challenges in tertiary institution due to the fact that complaint registration is difficult. In the case where the complaint registration is not difficult, responses to complaints tend to be quite slow. However, we considered building a system that will allow students make complaints in a much easier manner, and also keep accurate track of complaints made. A computerized complaint management system gives students the ability to air concerns without fear of being punished or penalised. The research methodology adopted for this study is Waterfall Methodology. In the system design, the data flow was modelled to capture the procedures used in the system. The tools used for the development are PHP programming language, JavaScript, Hyper Text Mark-up Language (HTML), Cascading Style Sheet (CSS), and MySQL. The MySQL server application served as the Database Management System (DBMS), while Visual Studio Code application served as the Integrated Development Environment (IDE). The ultimate achievement of this research is a web-based student complaint management software that is very effective and efficient in meeting the project objectives and the same time, user friendly.
\end{abstract}

Keywords: Integrated Development Environment, Cascading Style Sheet, Student Complaint Management System, Waterfall Methodology, Hyper Text Mark-up Language

\subsection{Introduction}

In order to have an effective educational system, there are some issues in the academic environment that need to be properly addressed. An example is the issue of complaints management system in the university. This issue has created a lot of problems for academic growth in various aspects of the educational system in the past. In order to support this approach, this project identifies a range of options that can be used to manage and resolve academic complaints. This includes the need for an administrator to make every effort to resolve potential or 
actual academic complaints as informally as possible in the first instance. Handling complaints involve listening, understanding, offering a solution, executing the solution, and then following up.

According to Collins English Dictionary, a complaint is a statement in which you express your dissatisfaction with a particular situation. Many students, especially new students, have many issues, which they are dissatisfied with, but they keep these issues bottled down because they do not have a means of laying their complaints, and even when they do, it takes long time for them to receive a reply, sometimes they never receive a reply at all. Most of the time, these issues end up becoming serious problems for them. As students advance in their academics, there tends to be more complicated issues surrounding their academics, from course registrations to information gathering.

In order to understand better the kind of complaints students have, we carried out a simple survey through oral interviews. About one hundred and twenty students were interviewed from different faculties in the school. We interviewed ten students from the faculty of Health Sciences, twenty five students from the faculty of Biosciences, fifty students from the faculty of Physical Sciences, fifteen students from the faculty of Arts, and twenty students from the faculty of Environmental Sciences. According to the statistics deduced, thirty five students complained about inadequate classrooms for lectures, nineteen students complained about malfunctioning of computers during Computer Based Examinations, twenty students complained about missing scripts, twenty students complained about absence of well-equipped laboratories for practical, ten students complained about lack of public addressing systems in classrooms, two students complained about lazy nonacademic staff members, six students complained about lecturers asking for and accepting bribes, and eight students complained about harassment by security personnel. Most of these students have tried to lay these complaints, but due to some reasons like not knowing the right channel to lay their complaints or tiredness from hectic lectures, they never do.

This system would help to reduce the difficulties that students experience in different areas of their school life. There are several benefits of laying complaints. They help the administrator to identify vital areas for service improvement, they help to keep senior management informed, they help to improve service, and above all, they help to improve complainant communication.

The design and implementation of web - based student complaint management system will help to maintain an effective, timely, and equitable complaint handling system which is easily accessible and offered to students at no charge. This project defines the policy and steps for handling and resolving complaints and for this process to take place, there must be automation of the system that will handle the complaints process and appeal method of registration.

\subsection{Statement of the Problem}

Today, the stress of competition, stagnant or shrinking markets and increasing internalisation as well as product substitutions are the main developments which cause the growing importance of well implemented and managed complaint management (Welz, 2006).

Some compliant systems are quite tiring, less efficient, and consume unnecessary manpower in comparison with a computerized system. The complaint system in most university is currently manual and even if it is automated 
the response time to complaints are longer. The system works this way: the student writes a formal letter to the Head of Department, irrespective of the type of complaint, explaining in details the issue. The Head of Department then forwards the letter to whoever is in charge of the complaints. These steps seem easy, but they are not because the entities are not solely in charge of complaints, so it might take a while for the letters to be redirected to the appropriate channel.

The researcher believe that the Design and Implementation of tertiary institution web-based student complaint management system will help in solving alleviating some of these problems that is facing students in the University environment. The basic problems facing complaint monitoring team in the tertiary institutions are:

a. Lack of Database: There is no database set up to screen transfer of complaint submitted on paper or as verbal representation. Therefore, there is no accurate record of students and their complaints. As a result, the use of manual systems is ineffective and unreliable.

b. Absence of Fitting Security: There is lack of fitting security and upkeep of the complaint record in the system that makes an avenue for disappointment and control of information. Suppose there is a little problem, all the documents of students' complaints could be lost. But with the computerized system, records could never be lost due to a small issue.

c. Low Performance: Poor performance of the manual system may lead to the missing or exploitation of the complaint by the staff or any member of the management.

d. Lack of Precision: There is lack of legitimate precise, concise data about the student's implicit character.

\subsection{Objectives of the Study}

The objectives of this study are the goals we hope to achieve when the new system is up and working. The objectives are:

1) To carry out a survey to understand better the kind of complaints students encounter in school and how complaints are approached by administrative personnel.

e. To implement a tertiary institution web-based student complaint management system that allows students to lay their complaints and receive rapid feedback in a much easier manner than the existing system with the use of HTML, JavaScript, PHP, and MySQL.

\subsection{Scope of the Study}

This study covers the procedure for managing complaints in tertiary institutions. The kinds of complaints that would be managed with this system include Issue of missing script, Collection of bribes from lecturers and absence of proper infrastructure for effective learning.

These complaints have been chosen to be covered in the scope because, from the statistics discovered, more students complained about these issues and they appear to be more pressing than the other complaints mentioned.

\subsection{Review of Related Literature}

Advocacy Research, (2021) opined that it is important that complaints are registered before they can be managed. When you have a complaint, it is important to get the details, and to provide evidence when you can 
and According to Kolsky (2015), 13\% of unhappy complainants will share their complaints with 15 or more people. Furthermore, only 1 in 25 unhappy complainants complain directly to the administrative head. According to this statistics by Kolsky, most complainants tend to either keep dissatisfied issues bottled down, or discuss the issues with other people who might become discouraged. Complaint Registration not only gives you the power to lay criticisms, it also gives room for rapid feedback.

According to Surbhi (2018), Management can be defined as the process of administering and controlling the affairs of the organization, irrespective of its nature, type, structure and size. It is an act of creating and maintaining such an environment wherein the members of the organization can work together, and achieve business objectives efficiently and effectively. By defining the words, we can say that Complaint Management is the process of controlling the issues of dissatisfaction or unhappiness expressed by complainants. Complaint management enables an efficient handling and controlling of issues laid by complainants. Management acts as a guide to a group of people working in the organization and coordinating their efforts, towards the attainment of the common objective (Surbhi, 2018).

It is very difficult to know what a person is thinking. It could be that majority of people are satisfied with your services, yet some of them have problems with it. This is why it is important to establish a functioning complaint management system, one that ensures good rapport with the people. In complaint management, strategies must be developed and it must be determined where complaints should be received, how one should react to feedback and which departments or individuals the criticism should be forwarded to (IONOS, 2019).

It is important to note that Salemme (2020) identifies ten steps to effective complaint management. The steps include the following:

1. Listen and Emphasize: When you start a complaint management process by simply hearing the complainant, you will establish a tone of empathy that will help the complainant trust you.

2. Become an Advocate: Empathy is only the first step, complainants also want to know that you will fix the problem and make them satisfied again, and otherwise they would not take the time to reach out.

3. Learn More: You need to know as much about the circumstances as possible.

4. Reiterate the Core Issues: When you listen to understand instead of listening to respond, you communicate a genuine interest in what the person has to say. It is called "active listening", and one of its core tenets is clarifying what you heard before you respond.

5. Identify the cause: Once you know the complaint, you can identify why it happened. Sometimes it will be the company's fault, in which case you'll need to move toward rectifying the issue.

6. Ask the Complainant to Suggest a Solution: Many complainants will already have an idea of what would "make it right", so ask them what they want.

7. Explain Next Steps: Whether you execute the solution yourself or not, your first job is to tell the complainant what happens next. Keeping them informed is another way to show you care.

8. Make It happen: Make sure you know what's happening and when, so if a complainant contacts you to ask about progress, you'll be able to update them.

9. Report Back: When the problem has been fixed, contact the complainant and let them know. 
10. Offer Something Extra: Post-resolution is an extremely effective time for companies to "go the extra mile".

An effective Complaint Management System is integral to providing quality complainant service. It helps to measure complainant satisfaction and is a useful source of information and feedback for improving services. Complainants are often the first to identify when things are not working properly (Ombudsman, 2020). Furthermore, worthy to note that Complaint Management Systems are extremely important in organizations where complainants are put first because, it helps to understand what complainants are thinking, it helps to establish more friendship between administrator and complainant, and above all, it ensures maximum complainant satisfaction. Complaint Management Systems have databases that keep track of complainant record and complaints. This can serve as a source of establishing a better connection between the complainant and administrator.

Complaints are a normal thing with organizations that have customers; in this case the customers are the students. According to Stone (2019), poor service organisations are a pain to do business with. Afify et al (2011), in their study developed a complaint management system that has the ability to minimize customer's dissatisfaction and it also encourages customers to participate in controlling the quality of the service provided. The system was developed as a Service-Oriented framework for e-complaint web-based that targets the charity life cycle. The cycle starts with distribution of different services that are provided through charity.

Aziz (2015), in his research work examined complaint management within a public governmental organisation. The study focused on the impact of complaint management processes on public service provision and on the potential of such processes in relation to governmental services development and improvement. The study took the form of a case study and involved a mixed methods research approach of both a survey of some public servants with a structured questionnaire, and a set of some more in-depth semi structured interviews with senior governmental officials drawn from a range of departments.

Alve (2017), in their study designed a web application for complaint tracking and resolving. The system was developed for managing various complaints in the hostel and college. The aim of the system was to make complaints easier to coordinate, monitor, track and resolve, and to provide organization with effective tool to keep records of complaint data to use data for identifying problem areas and to improve service. The system contains two modules for the user and the administrator. Therefore, there is a client-server relationship in the system. Each user has a unique identity which is user email ID.

\subsection{Analysis of the Existing System}

The present system records and manages complaints manually. The steps taken in managing different complaints in the present system differ. This research focuses on managing complaints mentioned in the scope. In the case of complaints on missing scripts, the present system follows a series of steps.

1. The complainant (student) writes a formal letter to the Head of Department, stating in details the issues being faced.

2. The Head of Department forwards the letter to the department in charge of results.

3. The department in charge of results forwards the letter to the ICT officer in charge of uploading results.

4. The ICT officer in charge then checks to know why the result was missing, and tries to correct it. 
Volume 9 Issue 8 August 2021

In the case of issues of collection of bribes from lecturers, a formal letter is written to the Head of Department. And in the case of lack of proper infrastructure for learning, a letter is written to the Head of Department, and he directs the complaints to the Vice Chancellor. The present system is not only stressful and time consuming. It also leads to delay in passing of complaints, especially complaints that needs to be attended to urgently.

This research work tries to bridge the gap by implementing a tertiary institution web-based student complaint management system that allows students to lay their complaints and receive rapid feedback in a much easier manner than the existing system. It tries to satisfy student's needs and simplify the work of the system administrator and lecturers.

\subsection{Analysis of the Proposed System}

The present system is prone to some problems as a result of the method used in processing and managing student's complaints. The proposed system will improve efficiency by reducing the time consumed in handling students' complaints. The analysis of the proposed system is discussed under two functional modules in the system. These modules are:

1. A web-based application used by complainants (students) to lay complaints, view their complaints history, make changes to their profile, and monitor how their complaints are being managed.

2. A terminal used by the system administrator to manage and process complaints, manage users, add new categories of complaints, view user logins, and respond to students' complaints.

\subsection{High Level Model of the Proposed System}

High level model is used to convey the core concepts and principle of an organisation in a simple way using concise descriptions. The advantage of developing a high level model is that it supports understanding, analysis, communication, and decision making of the system.

The complaint management system has two main modules. The diagram below describes the modules.

\section{STUDENT CMS}

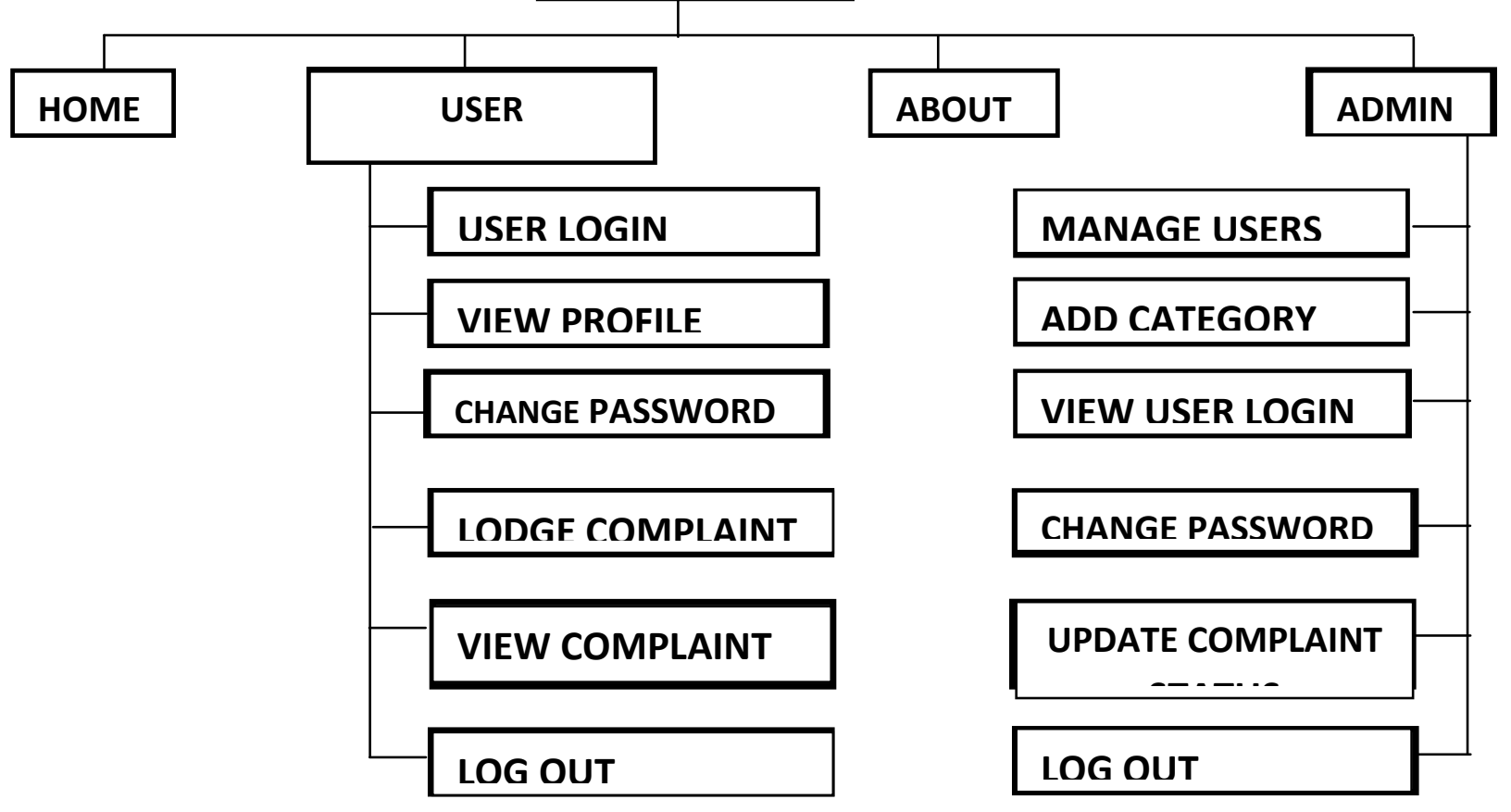

Fig.1: High Level Model of the Proposed System 


\subsection{Control Centre / Main Menu (Home Page Design)}

From the main menu display, the user can perform some functions. These functions include the following:

1. User Login: This module is used to $\log$ in users who have already been registered in the database. It also allows users to make changes to password in the case of forgotten password.

2. User Registration: This module is used to register students who do not yet have accounts.

3. Access Admin Panel: This module allows a user to log in to the admin panel. In this case, only the admin has access to this module.

4. View Software Description: This module allows users to visit the "about us" page, and view the software description and objectives.

5. Subscribe for Notifications: This module enables users to subscribe to newsletter in order to receive notifications whenever complaints have been attended to.

In summary, users (students) use the main menu to create an account and $\log$ in to their profiles. While, it allows the admin to log on to the admin panel and effectively manage complaints.

\subsection{Database Development Tool}

The database development tools used in the development of this project are MySQL and phpMyAdmin.

1. MySQL: MySQL is a database development tool that helps in creating a database that is used in storage and manipulation of data, clearly defining the relationship of data tables. Clients can make requests by typing specific SQL statements on MySQL, then the server will respond with the requested information and it will appear on the clients' side. It must be noted that SQL and MySQL are not the same. MySQL is a Relational Database Management Tool that implements a client-server model. Clients and servers communicate with the use of SQL, which is a domain - specific language. SQL stands for Structured Query Langúage.

2. phpMyAdmin: phpMyAdmin is a database management tool that is written in PHP. It was developed to handle the administration of MySQL over the web. PhpMyAdmin supports a wide range of operations on MySQL. Operations involving managing databases, tables, columns, relations, indexes, users, and permissions can be done via the user interface, while any SQL statement can still be directly executed.

\subsection{Database Design and Structure}

The database was designed using MySQL because it has the ability to hold and handle large numbers of records and tables. The tables below give the entire database used in this project.

Table 1: Complaints Record

\begin{tabular}{|c|c|c|c|c|}
\hline & Field Name & Data Type & Size & Description \\
\hline 1. & ComplaintNumber & Integer & 11 & Complaint number \\
\hline 2. & UserId & Integer & 11 & User id \\
\hline 3. & Category & String & 255 & Complaint category \\
\hline 4. & Subcategory & String & 255 & Complaint subcategory \\
\hline 5. & ComplaintType & String & 255 & Type of complaint \\
\hline
\end{tabular}


iJournals: International Journal of Software \& Hardware Research in Engineering (IJSHRE)

ISSN-2347-4890

Volume 9 Issue 8 August 2021

\begin{tabular}{|c|c|c|c|c|}
\hline 6. & Noc & String & 255 & Nature of complaint \\
\hline 7. & ComplaintDetails & String & 100 & Details of complaint \\
\hline 8. & ComplaintFile & String & 255 & File related to complaint \\
\hline 9. & RegDate & Date and Time & & Time stamp \\
\hline 10. & Status & String & 50 & Status of complaint \\
\hline 11. & LastUpdationDate & Date and Time & & Time stamp \\
\hline
\end{tabular}

\subsection{System Flowchart}

System flowcharts are a way of displaying how data flows in a system and how decisions are made to control events. Symbols are used to make illustrations.

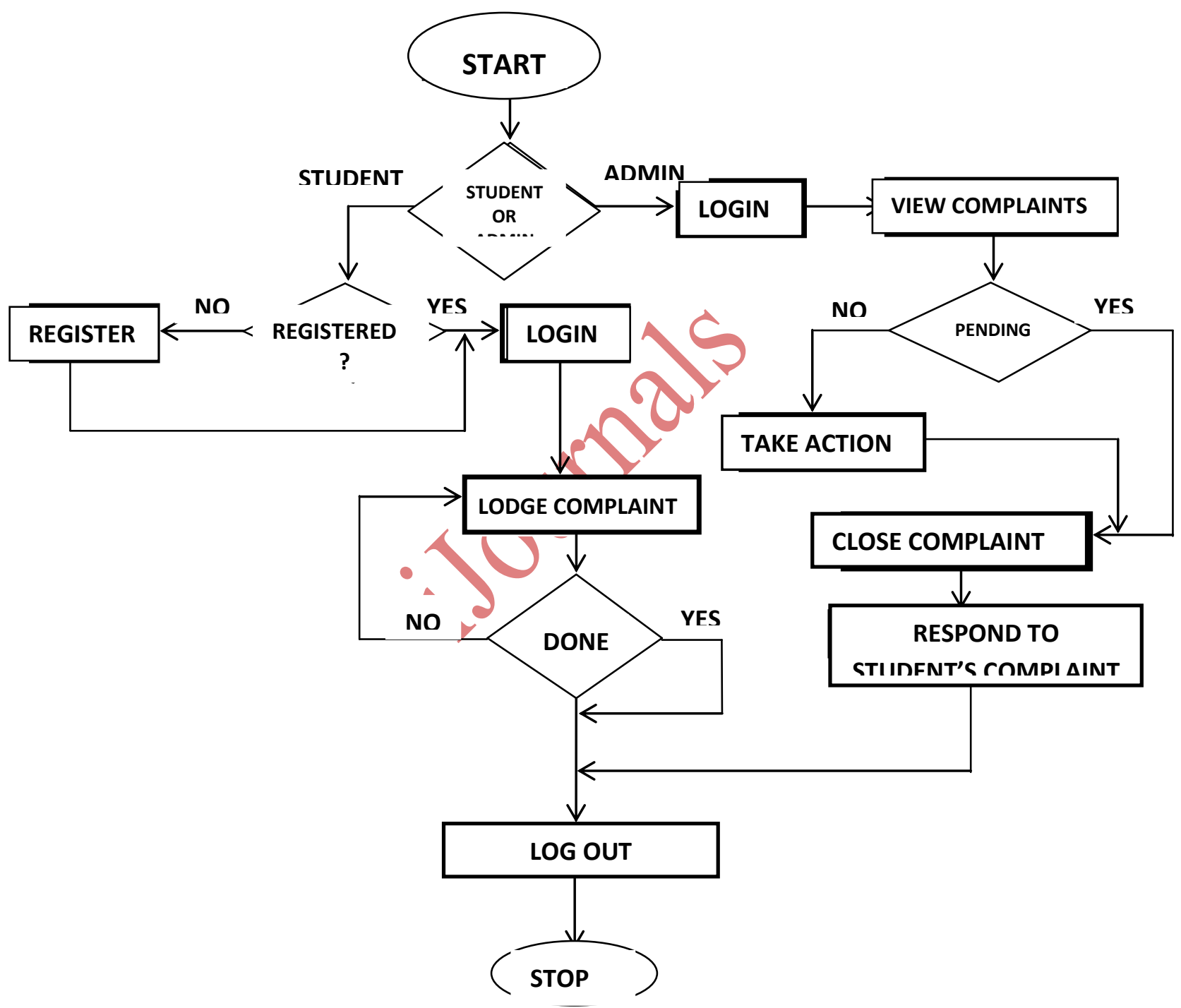

FIG.2: System Flowchart of the Proposed System

\subsection{Hardware and Software Requirements}

For effective use of the new system, the minimum requirements for the hardware components are Pentium4 board with $1 \mathrm{GHZ}$ speed, 1GB RAM size. A Hard Disk of 40GB and Display Unit of at least 14," 
Monitor (VGA) while the minimum operating system that must be used is Windows XP. Other software required includes Text editor like Visual Studio code, Notepad++, Sublime text, etc., A web browser and A database development tool like XAMPP.

\subsection{Program Development}

Program development of this system was done using the PHP and JavaScript programming languages while MySQL is use for the database.

\subsection{Summary}

Students not making complaints through the right channels can have a bad effect on the school name, therefore on the school at large. The right complaint system gives the schoola new level of control over operations, boosts efficiency, and help complaints to be voiced out properly. The wrong system however, can be a waste of money and a source of on-going frustration. Switching from manual complaint system to computerized complaint system can be quite difficult. There are many factors to consider and some pitfalls to avoid. However, the benefits surpass the difficulties, and it can really make it worth the time and effort. As a result, the need for a computerized complaint management system cannot be overemphasized.

\subsection{Conclusion}

At any point in time, a complaint management software such as the one proposed in this project, can help in always knowing what students think of the school system. The complaint management system can instantly allow a student to lodge a complaint, view their complaint status, and still receive feedback from the administrator. Detailed complaints stored in a database make it easier to retrieve respective complaints at any point in time. The administrator(s) might think they know exactly what student want, until complaint software is used.

\subsection{Recommendation}

The following are recommended in order to effectively use the new design:

1. The hardware and software requirements should be as specified.

2. Administrator(s) should be trained on how to manage complaints using the complaint management software.

\subsection{Application Areas}

This system is recommended for universities that need a lot of upgrading to be done, as it will help the universities in effective decision making.

\section{References}

Afify, E. \& Kadry, M. (2011). Model for Customer Complaint Management System using SOA. ProQuest.

Alve, S. (2017, April 4). Web Application for Complaint Tracking and Resolving. IRJET. 
iJournals: International Journal of Software \& Hardware Research in Engineering (IJSHRE)

Volume 9 Issue 8 August 2021

Aziz, R. (2015). The Effectiveness of Public Service Complaint Management Processes in Contexts of Autocratic Governance. Birmingham: University of Birmingham.

IONOS Inc. (2019). complaint management. Retrieved from https://www.ionos.com.

Ombudsman \& Queensl. (2021). Complaints management. Retrieved from https://www.ombudsman.qld.gov.au.

Salemme, I. (2020). Effective complaint management: 10 steps to customer success. Retrieved from https://www.pipefy.com.

Stone, M. (2019). Literature review on complaint management. Retrieved from https://www.link.springer.com.

Surbhi, S. (2018). management. Retrieved from https://www.businessjargons.com.

Welz, S. (2006). Complaint management-a short overview. Retrieved from https://www.grin.com.

\subsection{APPENDIX: SAMPLE OUTPUT}

\section{Sign In}

\section{Username}

\section{Password}

\section{Login}

FIG.3 LOGIN PAGE: The admin login form requests for username and password to grant a user authentication to access the main menu. 
iJournals: International Journal of Software \& Hardware Research in Engineering (IJSHRE)

Volume 9 Issue 8 August 2021

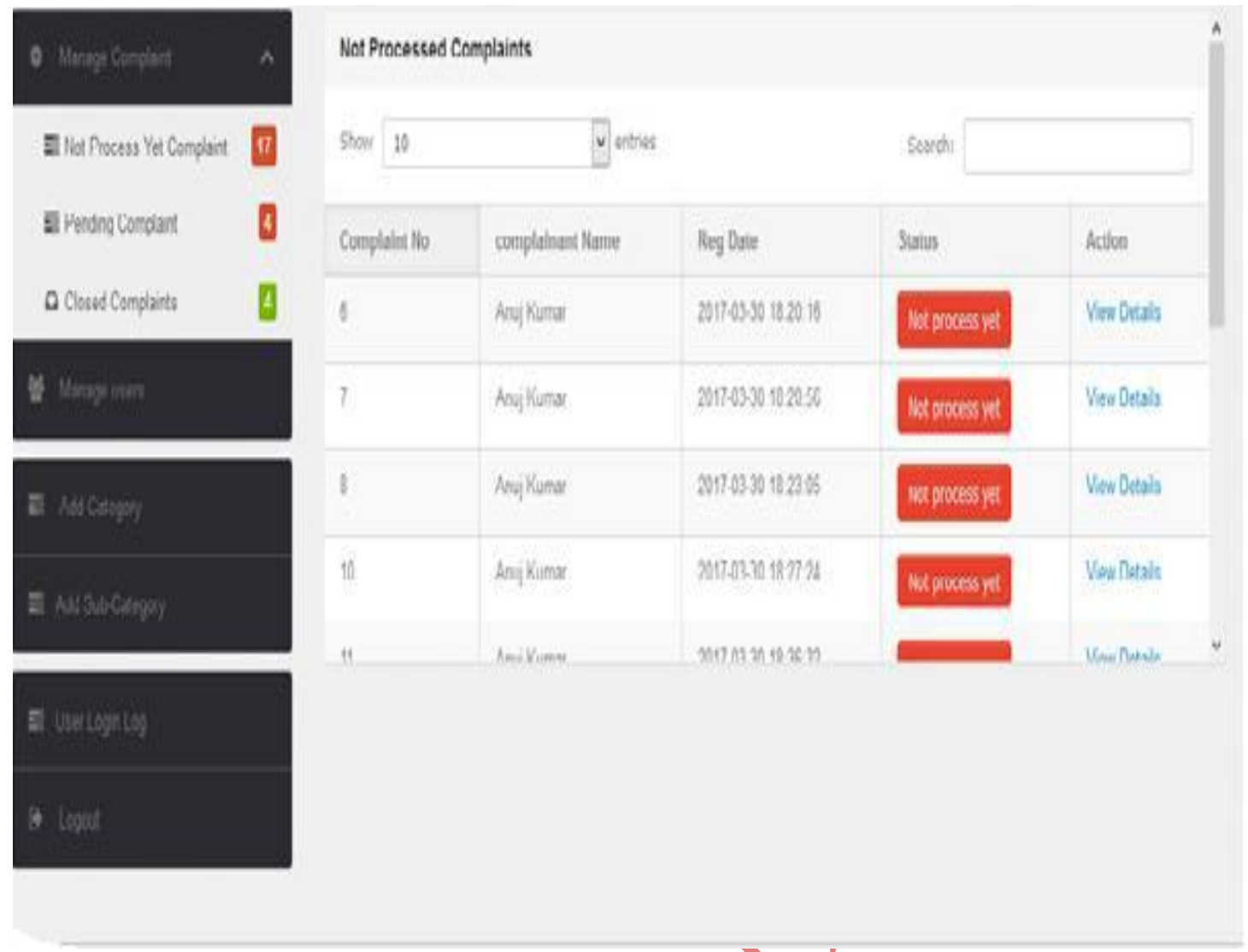

FIG.4: NOT PROCESSED COMPLAINTS PAGE: This menu gives the admin the list of complaints that have not been processed.

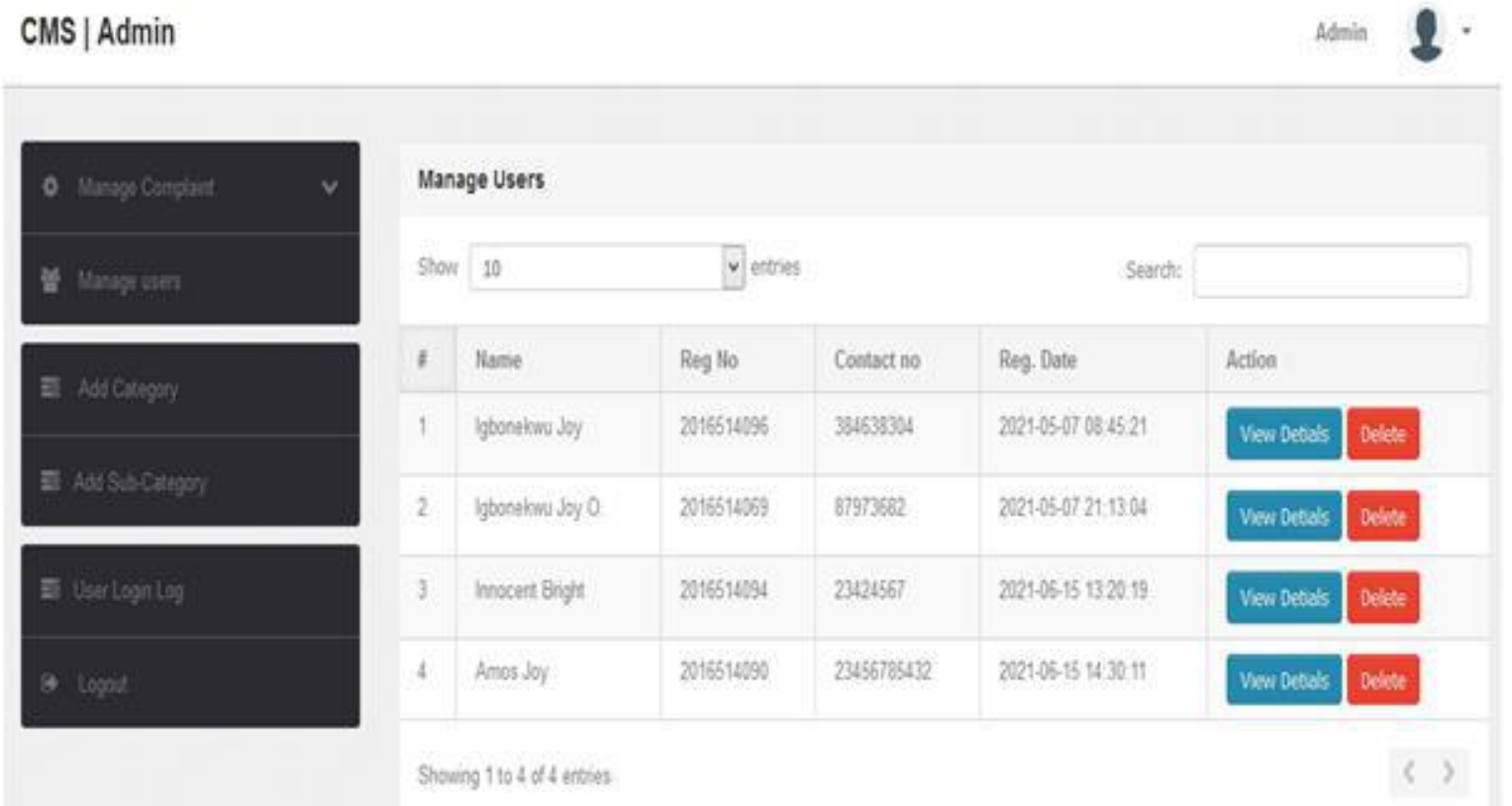

FIG.5: MANAGE USERS: This menu allows the admin to keep track of and delete the registered complaints. 
iJournals: International Journal of Software \& Hardware Research in Engineering (IJSHRE)

Volume 9 Issue 8 August 2021

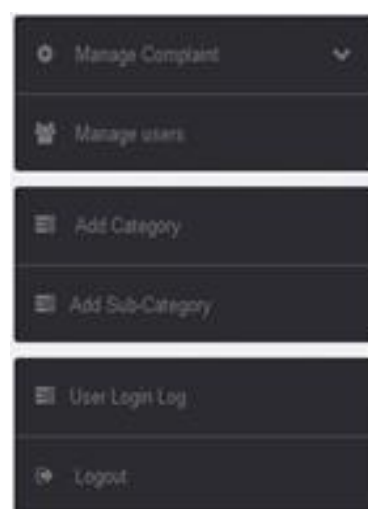

Category

Biter cotegory lane

Deseriptor

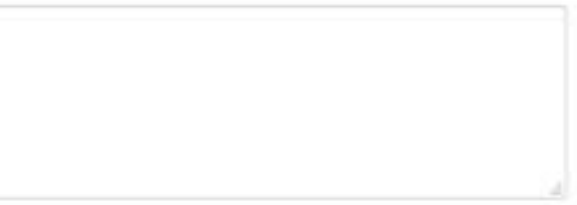

Coste

Manage Categories

Show 10 ventries

Sesch

- Category

Descriptice

Mssing Senpt

Students who have issues of masing scrips on the schod application can lay their complaints here

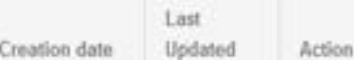

$2002+06-02$

$13: 15: 35$

FIG.6: ADD CATEGORY: From this menu, the admin can add new category of complaints

CMS|Admin

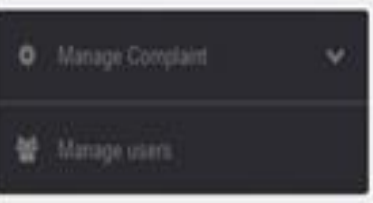

Manage Users

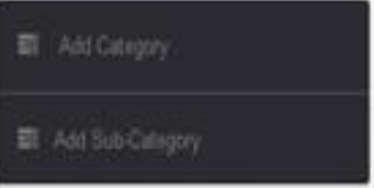

Show 10 $\checkmark$ enties

Serarch:

\begin{tabular}{|c|c|c|c|c|c|}
\hline 1 & Reg No & User IP & Login Time & Logout Time & Status \\
\hline 1 & 2017654234 & 1 & $2017.033+16.3907$ & & Faind \\
\hline 2 & $20155: 40 \%$ & 1 & 2017.03 .3198 .4122 & & Falied \\
\hline 3 & 2016514094 & 11 & 2017.033118 .4129 & & Faled \\
\hline 4 & 2015432679 & 1 & 2017.033118 .42 .12 & & Faled \\
\hline 5 & 2019675231 & 1 & $2017.0331+18.47 .51$ & & Faied \\
\hline 6 & 2009537212 & 1 & $2017.033+18.4754$ & & Faled \\
\hline 7 & 201854723 & 1 & $2017-02-3196.48: 11$ & & Faled \\
\hline
\end{tabular}

FIG.7: USER LOGIN LOG: This menu allows the admin to keep track of users who tried to login to the program. 


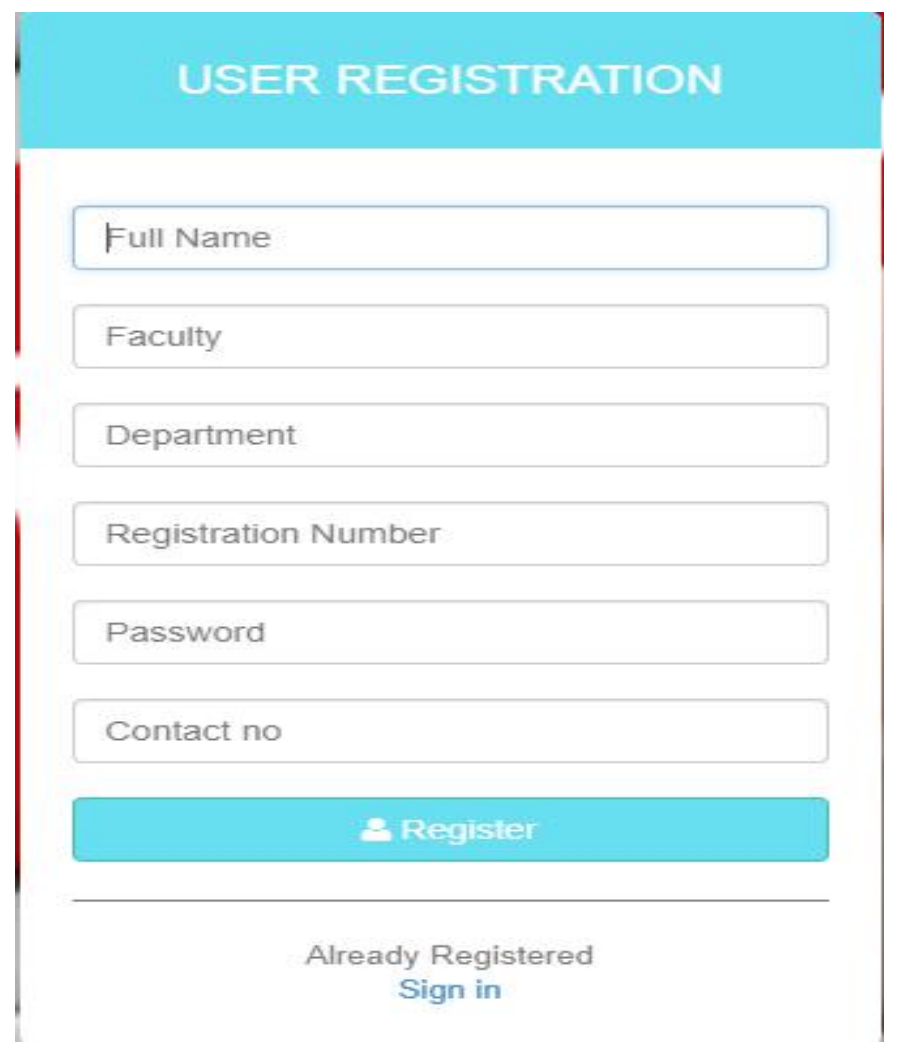

FIG.8: REGISTRATION PAGE: The registration page allows users to register their details into the database.

\section{SIGN IN NOW}

\section{Registration Number}

Password

Forgot Password?

\section{A SIGN IN}

Don't have an account yet?

Create an account

FIG.9: LOGIN PAGE: The login page asks for the user's registration number and password for authentication. 
iJournals: International Journal of Software \& Hardware Research in Engineering (IJSHRE) ISSN-2347-4890

Volume 9 Issue 8 August 2021

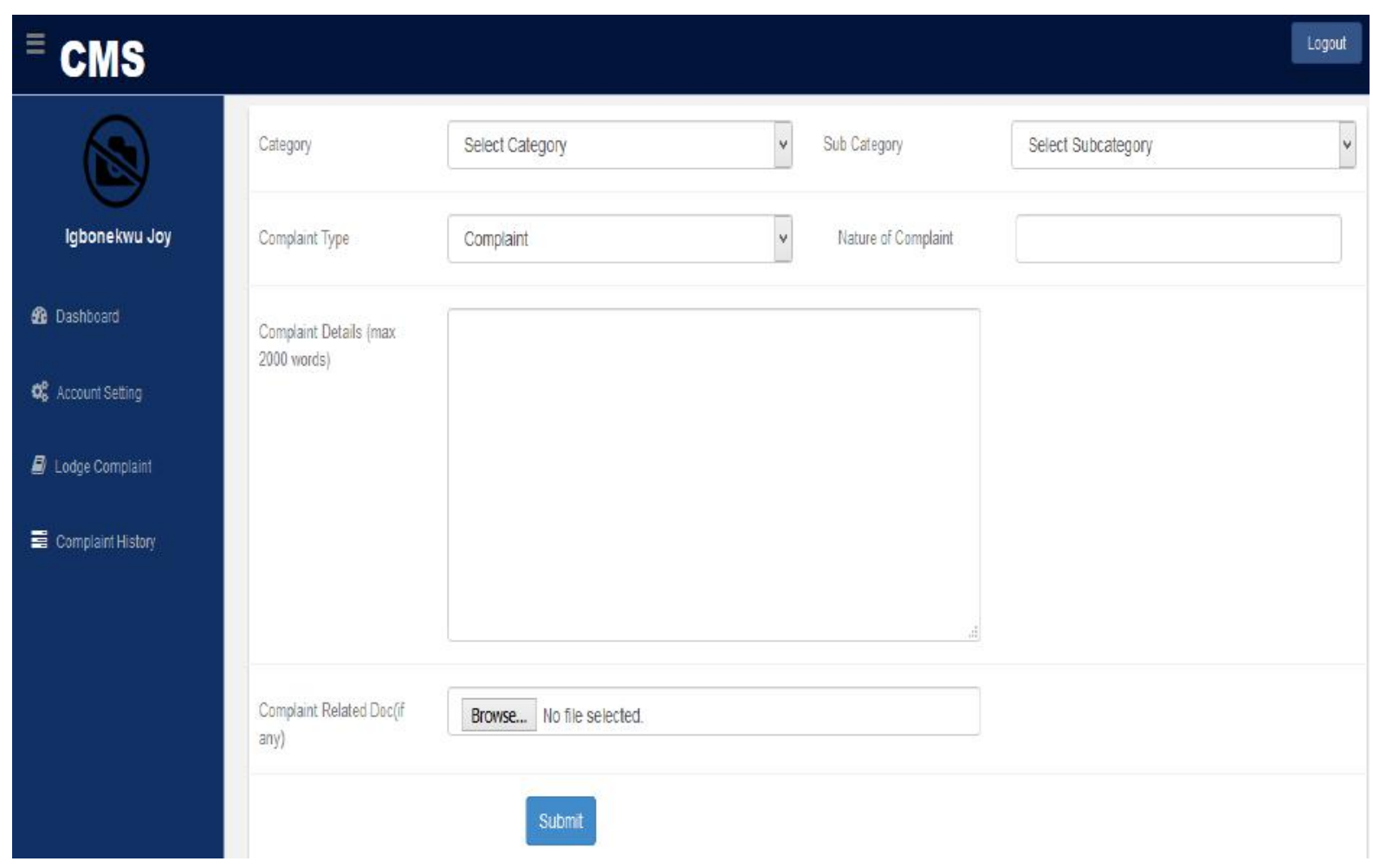

FIG.10: LODGE COMPLAINT: This allows the user to stat complaints in details.

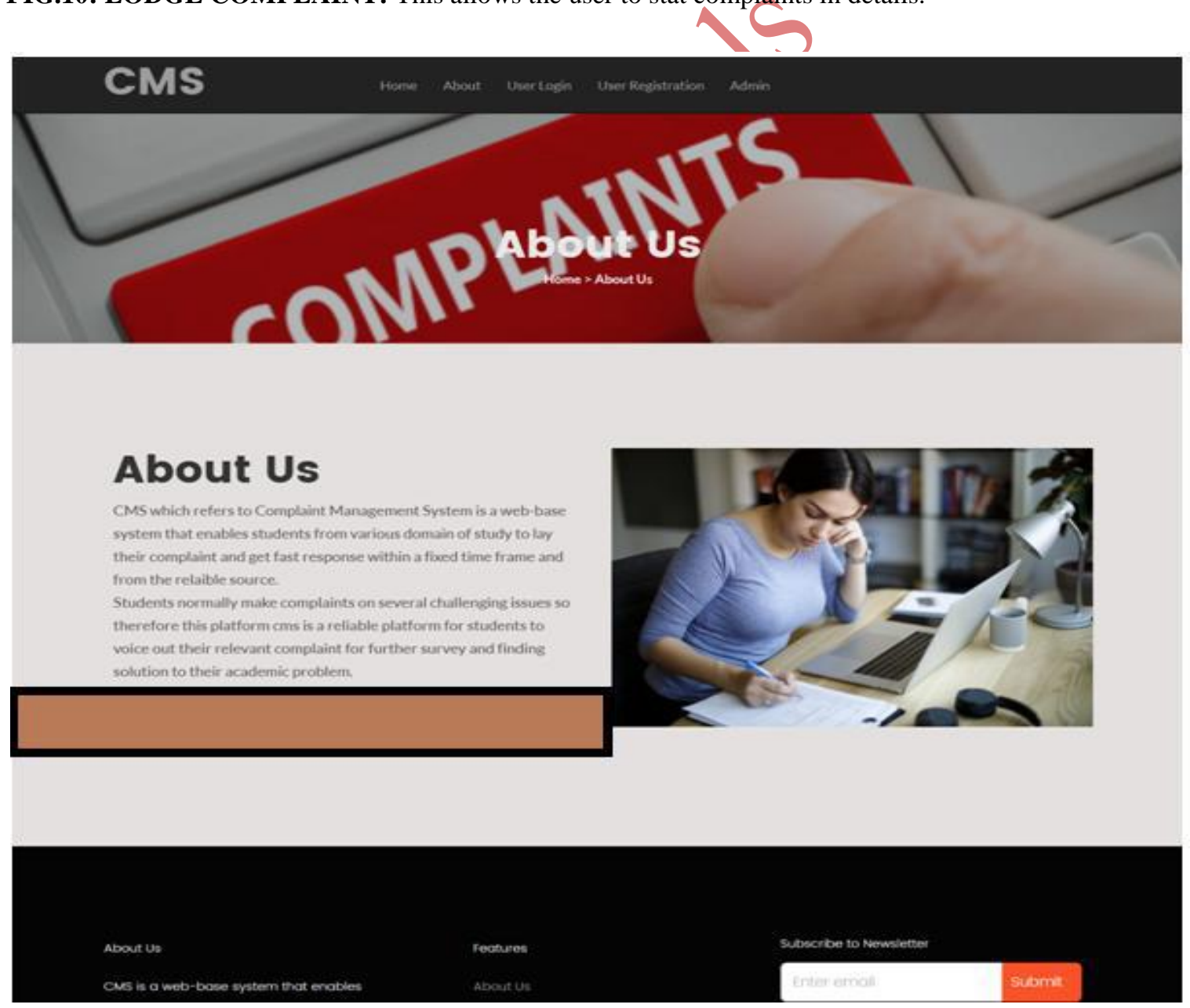

FIG.11: HOME PAGE 